\title{
Validity and Reliability of a Cardiopulmonary Resuscitation Attitudes Questionnaire Among Allied Health Profession Students
}

This article was published in the following Dove Press journal: Open Access Emergency Medicine

\author{
Alaa O Oteir $\mathbb{D}^{1,2}$ \\ Saddam F Kanaan $\mathbb{D D}^{3}$ \\ Mahmoud T Alwidyan (D) \\ Khader A Almhdawi $\mathbb{D D}^{3}$ \\ Brett Williams $\mathbb{D}^{2}$ \\ 'Department of Allied Medical Sciences, \\ Faculty of Applied Medical Sciences, \\ Jordan University of Science and \\ Technology, Irbid, Jordan; ${ }^{2}$ Department of \\ Paramedicine, Monash University, \\ Melbourne, Victoria, Australia; \\ ${ }^{3}$ Department of Rehabilitation Sciences, \\ Faculty of Applied Medical Sciences, \\ Jordan University of Science and \\ Technology, Irbid, Jordan
}

\begin{abstract}
Aim: To investigate the structural validity and internal consistency of a cardiopulmonary resuscitation attitudes questionnaire among Allied Health Professions (AHP) university students.
\end{abstract}

Methods: Structural validity of a 17-item questionnaire was tested using principal component analysis. A group of AHP university students completed the questionnaire. Internal consistency of the questionnaire was measured by Cronbach's $\alpha$.

Results: A total of 856 AHP students completed the questionnaire (mean age $=20.8( \pm 1.1)$ years, $74.0 \%$ were females). The analysis reduced a 17 -item questionnaire to an 11-item questionnaire. The final questionnaire had three distinct factors; (1) attitudes towards mouthto-mouth ventilation (MMV), (2) attitudes towards chest compressions (CC), and (3) the importance of cardiopulmonary resuscitation (CPR). It had factor loadings ranging from 0.629 to 0.878 and could explain $66 \%$ of the variance in the attitude. The questionnaire had acceptable internal consistency (Cronbach $\alpha=0.83 ; 95 \% \mathrm{CI}=81.5$ ) and was feasible with no floor or ceiling effect.

Conclusion: The 11-item CPR attitude questionnaire had acceptable structural validity and internal consistency and good parsimony and unidimensionality. The questionnaire can be used to measure the university students' attitude and assess the effectiveness of CPR training activities. Future studies are required to measure the responsiveness and applicability to other cohorts.

Keywords: cardiopulmonary resuscitation, attitude, questionnaire psychometric properties, allied health professions

\section{Introduction}

Early cardiopulmonary resuscitation (CPR) is associated with increased survival rates from out-of-hospital cardiac arrest (OHCA). ${ }^{1-3}$ Allied health profession (AHP) students deal with many patients daily during their clinical training; therefore, they are expected to attend and deal with life-threatening emergencies, including out-of-hospital cardiac arrests. ${ }^{4}$

International studies reported that trained individuals are more willing and confident to perform bystander $\mathrm{CPR},{ }^{5-7}$ which has been associated with increased survival rates and improved patient outcomes. ${ }^{3,8-14}$ Other studies indicated that females are less likely to perform bystander CPR compared to males. ${ }^{10,15,16}$ In addition, different studies reported that females were more likely to perform chest compressions compared to males. ${ }^{17}$ At the same time, other literature suggested that
Department of Allied Medical Sciences, Faculty of Applied Medical Sciences, Jordan University of Science and Technolgy, P.O. Box 3030, Irbid, 221 I0, Jordan

Email aooteir@just.edu.jo 
females are less willing to perform bystander CPR for male victims. ${ }^{16}$ Reported factors related to a negative attitude toward conducting CPR were fear of disease transmission, fear of legal liabilities, and fear of causing harm to patients. ${ }^{1,18-21}$

Attitude towards CPR is very important to measure. Although many studies have explored attitudes towards $\mathrm{CPR}$, to the best of our knowledge, there is no standardized measure of CPR attitudes. ${ }^{10,15,16} \mathrm{Lu}$ et al, for example, compared proportions of the positive attitudes towards $\mathrm{CC}$ and $\mathrm{MMV}$ in different scenarios. Participants had the options of "definitely yes", "definitely no" and "may be". ${ }^{15}$ Another study evaluated the attitude of university medical students towards CPR in various scenarios; $\mathrm{CC}$ and $\mathrm{MMV}, \mathrm{CC}$ with mask ventilation, and CC only. Participants had ten different scenarios and had to rate each scenario using a 4-point Likert scale of "definitely yes," "probably yes," "probably no," and "definitely no."16 Another study used an 8-item questionnaire to evaluate the willingness to perform CPR for strangers and family members, identifying the barriers to do so. ${ }^{18}$

It is essential to explore the attitudes towards CPR among AHP students, as these students can be witnessing bystanders, who can perform early CPR. Hence, a crosssectional study was conducted with a questionnaire composed of two sections: a demographic section and a 17-item attitude questionnaire. $^{22}$ This study found that students had a positive attitude to perform chest compressions (CC) CPR for strangers, relatives, and another gender. Also, students had less fear of infection when delivering $\mathrm{CC}$, compared to mouth-to-mouth ventilation (MMV) in these patient groups. Gender differences in attitude were also observed as females had a more positive attitude regarding $\mathrm{CC}$ for relatives and despite infection concerns, compared to males. Furthermore, females were more reluctant to perform MMV for males, strangers, and relatives. ${ }^{22}$

Validation of the current questionnaire will be useful to measure attitudes towards CPR among allied health profession students. This will also help to provide recommendations and action plans to overcome perceived barriers, aiming to increase the willingness to provide CPR, saving more lives. The current study, therefore, seeks to evaluate the new questionnaire psychometric properties, including structural validity and internal consistency, using principal component analysis (PCA). In addition, it evaluates the test-retest reliability, including interclass correlation, as well as the acceptability and feasibility of the questionnaire.

\section{Methods \\ Design}

A 17-items questionnaire was adapted from previous studies. ${ }^{10,15,16}$ A multidisciplinary expert panel of five researchers with relevant academic and clinical experience (from paramedicine, physical therapy, and occupational therapy professions) validated and approved the final version of a 17-item CPR attitude questionnaire by consensus. The questions aimed to evaluate the general attitude towards CPR, to perform MMV and chest compressions (CC) in various scenarios and for different groups. These groups included the other gender, strangers, relatives, and children. A group of AHP students in the Faculty of Applied Medical Sciences (FAMS) completed the questionnaire from April to May 2018. ${ }^{22}$

\section{Questions}

Each of the 17 items had a response composed of five choices (Likert scale) ranging from strongly disagree to strongly agree, with a score ranging from one to five. After reversing the negatively scored questions, a higher score indicates a more positive attitude.

\section{Sample and Setting}

A sample consisting of second, third, and fourth-year AHP university students were asked to participate in the study voluntarily. The FAMS offers four-year Bachelor of Science programs of nine AHP majors. Of these, we included eight majors: medical laboratory sciences, physiotherapy, occupational therapy and speech pathology, dental technology, allied dental science, radiologic technology, and optometry. ${ }^{4}$

Trained research assistants recruited the participants. They explained the study's purposes and collected surveys upon completion. First-year students were excluded as these students were still taking general university courses and were not enrolled in major-specific courses at the time of the study. Paramedicine students were also excluded from the study as they receive advanced simulation and clinical-based training on dealing with OHCA. All participants in this study signed informed consent forms and received no compensation for their participation. Terwee et al recommended sample size of at least 100 participants for variance stability in the principal component 
analysis. ${ }^{23}$ For internal consistency testing, a sample of at least 51 participants, with $\alpha=0.05$ and power of 0.80 , were sufficient to detect Cronbach's $\alpha$ of $0.5 .^{22}$ Moreover, there are inconsistencies in the literature regarding the required sample size for factor analysis with a ratio of participants to items ranging from $3: 1$ to $20: 1 .^{24}$ Another general rule of thumb suggested having at least 300 cases for factor analysis. $^{25}$ Our study included 856 participants and 17 items resulting in a ratio of 61 participants for each item (61:1), which is much higher than the recommended levels.

\section{Statistical Analysis}

Average scores were summarised as means and standard deviation. We assessed the structural validity of the questionnaire by the principal component analysis method. A principal component analysis was conducted to identify the components that are more relevant to each other. The analysis was conducted over three different stages, producing three models, where the third model represents the final model. Data appropriateness for factor analysis was tested using a Bartlett test of sphericity and Kaiser-Meyer-Olkin Measure of Sampling Adequacy. ${ }^{24}$ A minimum Guttman-Kaiser is greater than 1 was used to define the factors. ${ }^{26,27}$ Each item had to have a factor loading of 0.4 or greater to be included in its relative factor in the model, ${ }^{28}$ and a Pearson correlation of 0.3 or greater with the total score. ${ }^{24,25}$ Scores within each factor were computed where a higher score indicating a more likely positive attitude towards the corresponding factor. A p-value of 0.05 was considered statistically significant.

Cronbach alpha was used to assess the internal consistency of the questionnaire. As reliability depends on the number of items, a Cronbach alpha of $\geq 0.7$ was considered acceptable for scales including more than ten items, ${ }^{29}$ whereas a Cronbach alpha of $>0.5$ was deemed to be acceptable for scales including less than ten items. ${ }^{30}$

\section{Test-Retest Reliability}

To assess the consistency in responses, thirty participants responded to the questionnaire over one week. A minimum sample size of 10 subjected was required to achieve the ICC value of at least $0.7 .^{31}$ We used the intraclass correlation coefficient with two-way random effect and absolute agreement (ICC2,1). ${ }^{32}$ ICC2,1 was considered poor if the $\mathrm{s}$ value was less than 0.5 , moderate if between 0.5 and 0.75 , good if between 0.75 and 0.90 and excellent if the values were greater than $0.90 .^{32}$

\section{Acceptability and Feasibility}

The floor and ceiling effects of the questionnaire were determined by calculating the percentage of the participants who scored the lowest score and highest score. Floor or ceiling effects were present if $15 \%$ of the total participants scored the lowest and highest score. $^{23}$ The term ceiling effect is used in statistics to explain how the participants in a sample have ratings that are at or close to the possible upper limit. ${ }^{33}$ The feasibility is considered adequate if the response rate per element exceeded $95 \%{ }^{33}$

All statistical analyses were conducted using STATA (version 14.0 Stata Corporation, College Station, TX, USA).

\section{Ethical Approval}

The study was approved by the Institutional Review Board (IRB) at Jordan University of Science and Technology (JUST). (project number: AO-20180064). Moreover, this study was conducted in accordance with the Helsinki Declaration.

\section{Results \\ Exploratory Analysis of Principal Components}

The factor analysis included 856 complete questionnaires. Participants had a mean age of $20.8( \pm 1.1)$ years, and the majority were females (74.0\%). Only 181 (21.1\%) students in this study had previous CPR training. Moreover, the test-retest reliability found to be 0.86 (95\% CI: 0.71 , 0.93). No ceiling or floor effect as a total of $0.2 \%$ of participants scored the lowest and highest scores.

\section{Model I}

To prepare data for PCA, items were checked for interitem correlation. None of the items had a Pearson correlation $>0.65 .^{30}$ All 17 items were included in the PCA. Bartlett's test of sphericity $(\mathrm{p}<0.001)$ and Kaiser-MeyerOlkin testing (0.858) indicated that the component analysis was appropriate for this data set. ${ }^{24}$ This model included four factors and explained $64 \%$ of the variance. As there were observed differences in attitude between males and females, to remove items that had different latent constructs in females and males and to improve the use and interpretation of the scale, ${ }^{30}$ the remaining analyses were conducted with separate males and females groups. Three 
items were excluded as they had a correlation $<0.3$ with the total scores, leaving 14 items to enter the analysis.

\section{Model 2}

Fourteen items were entered in the PCA for each gender group. To reduce the variance, items were removed if they had a Pearson correlation $<0.3$ with the total score or if they were loaded onto different factors. Data were appropriate for factor analysis for each group (Bartlett's test of sphericity; $\mathrm{p}<0.001)$ and Kaiser-Meyer-Olkin testing (males:0.86; females:0.84). Both males and females' models included four factors explaining $64 \%$ and $59 \%$, respectively. Moreover, three items were removed as they loaded onto different factors between males and females, leaving 11 items loading on the same factors in each gender group, with all items having a factor loading $>0.4$ with the three factors having an eigenvalue $>1$.

\section{Model 3}

These 11 items were re-entered in a third model combining responses from males and females. Bartlett's test of sphericity $(p<0.001)$ and Kaiser-Meyer-Olkin testing (0.84) indicated that PCA was appropriate. The PCA resulted in three factors and explained $66 \%$ of the variance. ${ }^{34}$ No items cross-loaded onto more than one component and had acceptable communalities. General model factor loading ranged from 0.629 to 0.878 , explained $66 \%$ of the variance and had a good internal consistency (Cronbach alpha= 0.83, 1-sided 95\% CI: 0.815). Factor one, labeled as attitudes towards MMV, included five items with factor loadings ranging from 0.88 to 0.64 , explained $30 \%$ of the variance, and had a good internal consistency (Cronbach alpha $=0.86 ; 1$-sided 95\% CI 0.85). Factor two, labeled as attitudes towards $\mathrm{CC}$, included four items with factor loading ranging from 0.63 to 0.8 and explained $22 \%$ of the variance, with. The third factor, which was labeled as CPR importance, included two items only and had factor loadings of 0.841 and 0.767 , and explained $14 \%$ of the variance with an internal consistency of 0.62 (1-sided 95\% CI 0.57). A summary of the three factors, factor loadings, and communalities are available in Table 1

Table 2 includes the 17 items that composed the original questionnaire. The table identifies the excluded items as well as those that remained int the final model. (A clean copy of the questionnaire is provided in Appendix A)

Table 3 summarises the characteristics of the three factors. The final scale included could explain $66 \%$ of the variance, had an acceptable internal consistency $(\alpha=0.83$; $95 \% \mathrm{CI}=81.5$ ) and had a mean score of 38.6 (SD 6.7).

\section{Test-Retest Reliability}

The test-retest reliability of the questionnaire (ICC) was 0.9 (95\% CI: 0.8, 0.95). Indicating an excellent test-retest reliability.

\section{Acceptability and Feasibility}

The lowest score of the attitude questionnaire was 13 and scored by one participant $(0.12 \%)$. The highest score was 55 and scored by one participant $(0.58 \%)$. This indicates there is no ceiling and floor effect. Responses per item were $100 \%$, indicating the questionnaire is feasible.

Table I Rotated Factor Loadings (Pattern Matrix) and Unique Variances Sorted

\begin{tabular}{|c|c|c|c|c|}
\hline Item & Factor I (MMV) & Factor 2 (CC) & $\begin{array}{l}\text { Factor } 3 \text { (CPR } \\
\text { Importance) }\end{array}$ & Communalities \\
\hline I would provide MMV for strangers & 0.878 & 0.164 & 0.001 & 0.798 \\
\hline I would provide MMV for relatives & 0.857 & 0.130 & 0.126 & 0.767 \\
\hline I would provide MMV for the other gender & 0.790 & 0.120 & -0.057 & 0.642 \\
\hline I avoid providing MMV due to fear of infection* & 0.733 & 0.217 & -0.137 & 0.603 \\
\hline I would provide MMV for children & 0.640 & 0.272 & 0.241 & 0.542 \\
\hline I avoid providing CC due for fear of infection* & 0.192 & 0.803 & 0.101 & 0.692 \\
\hline I would provide CC for relatives & 0.246 & 0.769 & 0.266 & 0.723 \\
\hline I would provide CC for strangers & 0.325 & 0.737 & 0.253 & 0.713 \\
\hline I believe that CPR is harmful* & -0.058 & 0.629 & -0.192 & 0.435 \\
\hline $\begin{array}{l}\text { I would like to learn and practice CPR encouraged by } \\
\text { cultural values and religious beliefs }\end{array}$ & 0.050 & 0.103 & $0.84 I$ & 0.721 \\
\hline $\begin{array}{l}\text { I believe that CPR is important and can increase the } \\
\text { patients' survival }\end{array}$ & -0.047 & 0.228 & 0.767 & 0.643 \\
\hline
\end{tabular}

Abbreviations: MMV, mouth-to-mouth ventilation; CC, chest compressions; CPR, cardiopulmonary resuscitation; *, reversed; bold items belong to the same factor. 
Table 2 Included and Excluded Questionnaire Items

\begin{tabular}{|c|c|}
\hline Included Items & Excluded Items \\
\hline $\begin{array}{l}\text { - I would provide MMV for strangers } \\
\text { - I would provide MMV for relatives } \\
\text { - I would provide MMV for the other gender } \\
\text { - I avoid providing MMV due to fear of infection* } \\
\text { - I would provide MMV for children } \\
\text { - I avoid providing CC due for fear of infection* } \\
\text { - I would provide CC for relatives } \\
\text { - I would provide CC for strangers } \\
\text { - I believe that CPR is harmful* } \\
\text { - I would like to learn and practice CPR encouraged by cultural values and } \\
\text { religious beliefs } \\
\text { - I believe that CPR is important and can increase the patients' survival }\end{array}$ & $\begin{array}{l}\text { - I would provide CC for children } \\
\text { - I would provide CC for the other gender } \\
\text { - I would like to receive CPR by professionals when needed } \\
\text { - I have the confidence to perform CPR } \\
\text { - I have the knowledge and skills to perform CPR } \\
\text { - I avoid providing CPR as I am afraid of legal liabilities }\end{array}$ \\
\hline
\end{tabular}

Abbreviations: MMV, mouth-to-mouth ventilation; CC, chest compressions; CPR, cardiopulmonary resuscitation; *, reversed items.

Table 3 Characteristics of the Retained Factors $(\alpha=0.85, N=856)$

\begin{tabular}{|l|c|c|c|c|c|c|}
\hline Factor & Items & Eigenvalue & Internal Consistency & Explained Variance & Mean Score (SD) & Score Range \\
\hline Attitude towards MMV & 5 & 4.3 & 0.86 & 0.3 & $15(4.5)$ & $5-25$ \\
Attitude towards CC & 4 & 1.8 & 0.76 & 0.22 & $15(2.9)$ & $4-20$ \\
Importance of CPR & 2 & I.I & 0.62 & 0.14 & $8.4(1.4)$ & $2-10$ \\
Total & II & - & 0.85 & 0.66 & $38.6(6.7)$ & $13-55$ \\
\hline
\end{tabular}

Abbreviations: MMV, mouth-to-mouth ventilation; CC, chest compressions; CPR, cardiopulmonary resuscitation; SD, standard deviation.

\section{Discussion}

This study explored the validity and reliability, using PCA, of an attitude questionnaire completed by a group of AHP university students. The preliminary 17 -item questionnaire was designed to explore the attitudes towards CPR. ${ }^{22}$ The analysis reduced the 17-item questionnaire to an 11-item questionnaire. The final questionnaire had three distinct factors, including attitudes towards $\mathrm{MMV}, \mathrm{CC}$, and CPR's importance. The questionnaire has adequate unidimensionality and acceptable internal consistency.

The factor analysis results, including high item loading scores, no cross-loadings, and moderately high communalities, highlight good parsimony and unidimensionality. ${ }^{35}$ The final questionnaire had an acceptable internal consistency (Cronbach $\alpha: 0.83$ ) and explained $66 \%$ of the total attitude variance. The final model was reached following multistage analysis. Items were removed because of correlations of $<0.3$ with the total score and/or those with factor loadings of $<0.4$. So, the removed items were almost redundant and may be not related to the construct of "Attitude". Therefore, by doing so, we made the questionnaire more applicable without affecting its ability to assess the attitude construct.
To the best of our knowledge, there was no pre-existing standardized questionnaire regarding attitude towards CPR. The piloted questionnaire was validated and designed using rigorous methods, including confirming construct and face validity, piloting and relying on previously published evidence. Moreover, dividing the data into female and male subsets may be an uncommon method for conducting factor analysis; however, this helped the removal of items with low loading in both genders. This also resulted in a single questionnaire that is appropriate for both genders and can facilitate use and interpretation. The model also could explain a large proportion of variance and had a acceptable internal consistency. Furthermore, as all factors had acceptable internal consistencies, researchers can produce total and subscores to ease comparisons between various groups. This will be more interpretable and allow conducting inferential statistics, including hypothesis testing and regression analysis, to identify the factors associated with the attitude towards MMV, CC, and CPR in general.

Many reported factors might influence the willingness to perform CPR. Training is a key factor to improve participants' attitudes towards CPR. Previous studies 
reported that trained individuals are more willing and confident to perform bystander CPR..$^{5-7}$ In this study, trained students were more willing to provide MMV to strangers compared to untrained ${ }^{22}$ However, there was no difference regarding $\mathrm{CC}^{22}$

Furthermore, gender differences may also influence the willingness to perform $\mathrm{CPR} .^{36,37}$ Other factors were reported as a negative attitude toward bystander CPR include fear of disease transmission, fear of legal liability, and fear of causing harm to patient. ${ }^{1,18-21}$

Besides, willingness to perform MMV and/or CC can be influenced by the age of the individual who is experiencing the cardiac arrest or whether this individual is a relative or a stranger. For example, people were willing to provide both MMV and CC for children. ${ }^{36}$ Perhaps bystanders would be empathetic towards children, more willing to provide CPR, and be less concerned about the perceived barriers, including cultural concerns and fear of legal liabilities. Studies also revealed that individuals are more inclined to perform CPR for their relatives compared to strangers. ${ }^{18,22}$ This can be explained by that bystanders would be more comfortable working with their relatives than strangers, focusing on saving their lives more than being worried about legal liabilities. ${ }^{16}$

\section{Clinical/Preclicncal Implications}

Despite the unsatisfactory training rate among participants ( $21.1 \%$ only), participants had positive attitudes towards the importance of CPR (the last two items in the questionnaire); $79.2 \%$ were willing to learn and practice CPR, and $87.5 \%$ indicated that CPR is important and can increase patient survival. ${ }^{22}$ Training of these students will most likely improve their attitude towards MMV and CC. Therefore, to increase these training rates, we collaborated with other faculty members and university administrators and organised several free CPR training sessions and "CPR days". Furthermore, the paramedicine staff trained their paramedicine students to conduct CPR training. This helped improving CPR knowledge and training rates among their faculty and university colleagues, among students and staff at different universities and schools, and among individuals in local communities.

\section{Future Research}

Future studies are required to further test the questionnaire using confirmatory factor analysis and evaluate other psychometric properties. This can also be tested among different groups of students as well as among AHP professionals and community members of the public.

The produced questionnaire provides a valid and reliable tool to assess attitude various factors among AHP university students and potential lay community members, health care clinicians, police, firefighters, and healthcare providers in general. However, researchers should consider their included population's sociodemographic factors to adjust for in data collection and the analysis. Furthermore, we speculate that attitude towards CPR, especially MMV, may be influenced by the spread of infectious diseases such as coronavirus (COVID-19). Bystanders may be more reluctant to perform MMV due to their infection concerns. This factor should also be considered when conducting similar studies among students, healthcare professionals, and the general public.

These studies' findings can explore the commonly perceived barriers toward CPR and the factors associated with willingness to perform $\mathrm{CPR}$, which will help tailor strategies to overcome these barriers aiming to increase training rates, willingness and likelihood of performing CPR, which ultimately increase the survival rates of OHCA. ${ }^{8-10,38}$

\section{Limitations}

The study was a cross-sectional study, and inherent limitations are potential. The survey was also self-reported; a reporting bias is therefore possible. Moreover, the findings were based on participants' attitudes, which may be different from a person to another and can be based on individuals' previous experiences.

\section{Conclusion}

The final questionnaire had 11 items divided into three distinct factors, including attitudes towards MMV, CC and the importance of CPR. The final questionnaire had a good internal consistency and could explain $66 \%$ of the total variance. The high item loading scores, no cross-loadings, and moderately high communalities highlight good parsimony and unidimensionality. Studying attitudes towards CPR is very important to this line of research in Jordan and worldwide. Findings from PCA can provide a short questionnaire with good dimensionality and reliability.

\section{Acknowledgments}

Jordan University of Science and Technology funded this project, project number: 20180064. We would like to thank 
our colleagues, research assistants and participating students for their participation and cooperation during our study.

\section{Disclosure}

The authors declare no conflicts of interest in this work.

\section{References}

1. Bray JE, Smith K, Case R, Cartledge S, Straney L, Finn J. Public cardiopulmonary resuscitation training rates and awareness of hands-only cardiopulmonary resuscitation: a cross-sectional survey of Victorians. Emergency Med Australas. 2017;29(2):158-164. doi: $10.1111 / 1742-6723.12720$

2. Kanstad BK, Nilsen SA, Fredriksen K. CPR knowledge and attitude to performing bystander CPR among secondary school students in Norway. Resuscitation. 2011;82(8):1053-1059. doi:10.1016/j. resuscitation.2011.03.033

3. Hasselqvist-Ax I, Riva G, Herlitz J, et al. Early cardiopulmonary resuscitation in out-of-hospital cardiac arrest. $N$ Engl $J$ Med. 2015;372(24):2307-2315. doi:10.1056/NEJMoa1405796

4. Oteir AO, Almhdawi KA, Kanaan SF, Alwidyan MT, Williams B. Cardiopulmonary resuscitation level of knowledge among allied health university students in Jordan: a cross-sectional study. $B M J$ Open. 2019;9(11):e031725. doi:10.1136/bmjopen-2019-031725

5. Urban J, Thode H, Stapleton E, Singer AJ. Current knowledge of and willingness to perform Hands-Only ${ }^{\mathrm{TM}} \mathrm{CPR}$ in laypersons. Resuscitation. 2013;84(11):1574-1578. doi:10.1016/j.resuscitation.2013.04.014

6. Berdowski J, Berg RA, Tijssen JGP, Koster RW. Global incidences of out-of-hospital cardiac arrest and survival rates: systematic review of 67 prospective studies. Resuscitation. 2010;81(11):1479-1487. doi:10.1016/j.resuscitation.2010.08.006

7. Bobrow BJ, Vadeboncoeur TF, Spaite DW, et al. The effectiveness of ultrabrief and brief educational videos for training lay responders in hands-only cardiopulmonary resuscitation: implications for the future of citizen cardiopulmonary resuscitation training. Circ Cardiovasc Quality Outcomes. 2011;4(2):220-226. doi:10.1161/ CIRCOUTCOMES.110.959353

8. Yang C-W, Yen Z-S, McGowan JE, et al. A systematic review of retention of adult advanced life support knowledge and skills in healthcare providers. Resuscitation. 2012;83(9):1055-1060. doi:10.1016/j.resuscitation.2012.02.027

9. Hopstock LA. Cardiopulmonary resuscitation; use, training and self-confidence in skills. A self-report study among hospital personnel. Scand J Trauma Resusc Emerg Med. 2008;16(1):18. doi:10.1186/1757-7241-16-18

10. Van de Velde S, Roex A, Vangronsveld K, et al. Can training improve laypersons helping behaviour in first aid? A randomised controlled deception trial. Emergency Med J. 2013;30(4):292-297. doi:10.1136/ emermed-2012-201128

11. Sayre MR, Berg RA, Cave DM, Page RL, Potts J, White RD. Handsonly (compression-only) cardiopulmonary resuscitation: a call to action for bystander response to adults who experience out-ofhospital sudden cardiac arrest: a science advisory for the public from the American Heart Association Emergency Cardiovascular Care Committee. Circulation. 2008;117(16):2162-2167. doi:10.1161/CIRCULATIONAHA.107.189380

12. Wissenberg M, Lippert FK, Folke F, et al. Association of national initiatives to improve cardiac arrest management with rates of bystander intervention and patient survival after out-of-hospital cardiac arrest. JAMA. 2013;310(13):1377-1384. doi:10.1001/jama.2013.278483

13. Vaillancourt C, Kasaboski A, Charette M, et al. Barriers and facilitators to CPR training and performing CPR in an older population most likely to witness cardiac arrest: a national survey. Resuscitation. 2013;84(12):1747-1752. doi:10.1016/j.resuscitation.2013.08.001
14. Soar J, Maconochie I, Wyckoff MH, et al. 2019 international consensus on cardiopulmonary resuscitation and emergency cardiovascular care science with treatment recommendations: summary from the basic life support; advanced life support; pediatric life support; neonatal life support; education, implementation, and teams; and first aid task forces. Circulation. 2019;140(24):e826-e880. doi:10.1161/ CIR.0000000000000734

15. Carney NA, Petroni GJ, Luján SB, et al. Postdischarge care of pediatric traumatic brain injury in argentina: a multicenter randomized controlled trial. Pediatr Crit Care Med. 2016;17(7):658-666. doi:10.1097/PCC.0000000000000772

16. Chew KS, Yazid MNA. The willingness of final year medical and dental students to perform bystander cardiopulmonary resuscitation in an Asian community. Int $J$ Emerg Med. 2008;1(4):301. doi:10.1007/s12245-008-0070-y

17. Lu C, Jin Y-H, Shi X-T, et al. Factors influencing Chinese university students' willingness to performing bystander cardiopulmonary resuscitation. Int Emerg Nurs. 2017;32:3-8. doi:10.1016/j. ienj.2016.04.001

18. Coons SJ, Guy MC. Performing bystander CPR for sudden cardiac arrest: behavioral intentions among the general adult population in Arizona. Resuscitation. 2009;80(3):334-340. doi:10.1016/j. resuscitation.2008.11.024

19. Kleinman ME, Brennan EE, Goldberger ZD, et al. Part 5: adult basic life support and cardiopulmonary resuscitation quality: 2015 American Heart Association guidelines update for cardiopulmonary resuscitation and emergency cardiovascular care. Circulation. 2015;132(18 suppl 2):S414-S435. doi:10.1161/ CIR.0000000000000259

20. Savastano S, Vanni V. Cardiopulmonary resuscitation in real life: the most frequent fears of lay rescuers. Resuscitation. 2011;82 (5):568-571. doi:10.1016/j.resuscitation.2010.12.010

21. Malta Hansen C, Rosenkranz SM, Folke F, et al. Lay bystanders ${ }^{\circ}$ perspectives on what facilitates cardiopulmonary resuscitation and use of automated external defibrillators in real cardiac arrests. $J \mathrm{Am}$ Heart Assoc. 2017;6(3):e004572. doi:10.1161/JAHA.116.004572

22. Oteir A, Almhdawi K, Kanaan S, Alwidyan M, Williams B. Attitudes towards CPR among allied health students in Jordan: a cross-sectional study. Australas J Paramed. 2020;17.

23. Terwee CB, Bot SDM, de Boer MR, et al. Quality criteria were proposed for measurement properties of health status questionnaires. J Clin Epidemiol. 2007;60(1):34-42. doi:10.1016/j. jclinepi.2006.03.012

24. Williams B, Onsman A, Brown T. Exploratory factor analysis: a five-step guide for novices. Australas J Paramed. 2010;8(3):3. doi:10.33151/ajp.8.3.93

25. Tabachnick BG, Fidell LS, Ullman JB. Using Multivariate Statistics. USA: Pearson Boston, MA; 2007.

26. Watson R. Publishing the results of factor analysis: interpretation and presentation. J Adv Nurs. 1998;28(6):1361-1363. doi:10.1046/j.13652648.1998.00857.x

27. Kaiser HF. The application of electronic computers to factor analysis. Educ Psychol Meas. 1960;20(1):141-151. doi:10.1177/ 001316446002000116

28. Costello AB, Osborne J. Best practices in exploratory factor analysis: four recommendations for getting the most from your analysis. Pract Assess Res Eval. 2005;10(1):7.

29. Nunnally JC. Psychometric Theory: $2 d$ Ed. USA: McGraw-Hill; 1978.

30. Darlow B, Perry M, Mathieson F, et al. The development and exploratory analysis of the back pain attitudes questionnaire (Back-PAQ). BMJ Open. 2014;4(5):e005251. doi:10.1136/bmjopen2014-005251

31. Bujang MA, Baharum N. A simplified guide to determination of sample size requirements for estimating the value of intraclass correlation coefficient: a review. Arch Orofacial Sci. 2017;12:1. 
32. Koo TK, Li MY. A guideline of selecting and reporting intraclass correlation coefficients for reliability research. J Chiropr Med. 2016;15(2):155-163. doi:10.1016/j.jcm.2016.02.012

33. Everitt B, Skrondal A. The Cambridge Dictionary of Statistics. Vol. 106. Cambridge University Press Cambridge; 2002.

34. Peterson RA. A meta-analysis of variance accounted for and factor loadings in exploratory factor analysis. Mark Lett. 2000;11 (3):261-275. doi:10.1023/A:1008191211004

35. Pett MA, Lackey NR, Sullivan JJ. Making Sense of Factor Analysis: The Use of Factor Analysis for Instrument Development in Health Care Research. USA: Sage; 2003.
36. Lu C, Jin Y, Meng F, et al. An exploration of attitudes toward bystander cardiopulmonary resuscitation in university students in Tianjin, China: a survey. Int Emerg Nurs. 2016;24:28-34. doi:10.1016/j.ienj.2015.05.006

37. Frei H-C, Hotz T, Cadosch D, Rudin M, Käch K. Central head perforation, or "cut through," caused by the helical blade of the proximal femoral nail antirotation. J Orthop Trauma. 2012;26(8): e102-e107. doi:10.1097/BOT.0b013e31822c53c1

38. Cooper S, Johnston E, Priscott D. Immediate life support (ILS) training: impact in a primary care setting? Resuscitation. 2007;72 (1):92-99. doi:10.1016/j.resuscitation.2006.06.004

\section{Publish your work in this journal}

The Open Access Emergency Medicine is an international, peerreviewed, open access journal publishing original research, reports, editorials, reviews and commentaries on all aspects of emergency medicine. The manuscript management system is completely online and includes a very quick and fair peer-review system, which is all easy to use. Visit http://www.dovepress.com/testimonials.php to read real quotes from published authors. 